\title{
A reanalysis of the collapse of the Heidegroeve: subsidence over an abandoned room and pillar mine due to previously unknown mine workings underneath
}

\author{
Roland Frits Bekendam \\ GeoControl, Maastricht, 6226 WG, the Netherlands \\ Correspondence: Roland Frits Bekendam (info@geocontrol.nl)
}

Published: 22 April 2020

\begin{abstract}
In the region of Maastricht, both in the Netherlands and in Belgium, about 400 room and pillar mines have been excavated in weak Upper-Cretaceous limestones. Pillar instability has resulted in a number of largescale collapses and serious surface subsidence with faulting and sinkhole formation. The Heidegroeve used to be a very stable mine for more than 50 years, until pillars started to fracture and spall unexpectedly in the summer of 1987. The collapse of the abandoned mine occurred in June 1988, and was initially detected when faults and sinkholes had formed at the surface.

Originally it was postulated that just creep deformation inside this mine was the main cause. However, a stability analysis revealed that all pillars inside the collapse area showed sufficient safety factors and should still be intact, while the weakest part, with several pillars of insufficient strength, had been fractured but is still standing. In the vicinity of the collapse area mines have been excavated at a lower level. Therefore it was postulated that the collapse of the Heidegroeve was related to an unknown and inaccessible continuation of these mine workings underneath. Indeed, recent, rather adventurous fieldwork revealed a downward collapseinduced fault giving access to open galleries and collapse structures about $3.5 \mathrm{~m}$ below the Heidegroeve. Inside the collapse area of the Heidegroeve itself, accessible through openings between the debris fragments, severe tilting of gallery floors was observed, which was probably brought about by punching of pillars of the lower mine.

This case study with an unusual result shows that great care must always be taken in the analysis of the stability of mines and the assessment of the risk of surface subsidence.
\end{abstract}

\section{Introduction}

In the Dutch- and Belgian provinces of Limburg the rocks of Maastrichtian age contain some layers of calcarenite which are free of flint. These layers have been mined by room and pillar methods since the Middle Ages to give an attractive building stone, despite its low strength (UCS generally of 1.5-3 MPa). The mines are situated at depths of $50 \mathrm{~m}$ at most and range in size from a few galleries to labyrinths of $85 \mathrm{ha}$. In the past the rock was excavated by means of handsaws, picks and chisels. At present the building stone is mined only in one underground quarry using electric chainsaws.

The now abandoned mines, often containing paintings, drawings and sculptures, are of great historical and cultural value, and their touristic exploitation (at least 500000 visitors per year) is economically important for the region. The stability of the mines is not only important because of the touristic exploitation but also because several of these are located below buildings, roads and other surface structures.

Various types of instability in the mines can induce subsidence. This paper concentrates on the characteristics of large-scale pillar collapses and the induced surface subsidence, with the Heidegroeve as a case study with some unusual aspects. 
(a)

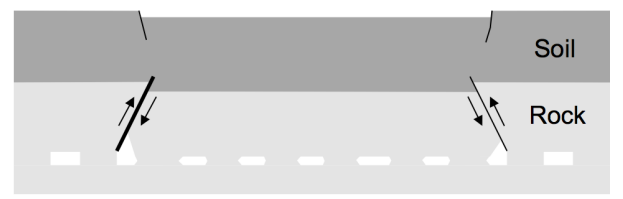

(b)

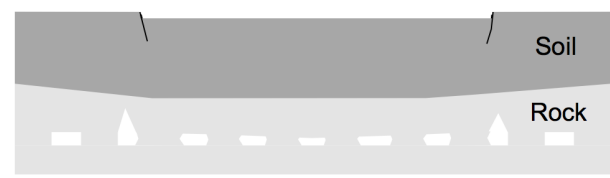

Figure 1. The two main types of large-scale pillar collapse in the limestone mines: downward movement of the rock overburden along collapse-induced faults (a) and by mere deflection of the rock overburden (b).

\section{Pillar instability and large-scale collapse}

\subsection{General characteristics}

If the average vertical stress on a pillar exceeds its (longterm) strength, the strain becomes so large that cracks start to develop at the top and bottom edges and spalling begins to occur. Upon further strain the pillar is separated into an hourglass shaped core and parted pillar sides. Such a pillar is denoted as completely failed. However, such a pillar still has some residual strength.

The vertical strain of a failed pillar, reduced in strength, is often limited due to stress transfer to surrounding pillars. Collapse, i.e. compression of several decimetres to metres and disruption, does not occur. However, due to this load transfer other pillars may start to fail as well. By this domino effect pillar failure may affect a whole mine or a major part of it. Eventually a sudden large-scale collapse may result and in a few seconds several hectares of a mine system are destroyed. Creep deformation must be of importance, because several collapses occurred tens of years or even more than 100 years after the end of the excavation. In Limburg at least ten of such events have occurred in the past (Bekendam, 1998). The most tragic collapse (4 ha) was in 1958 in the Roosburg mine near the village of Zichen in Belgium, when 18 persons, working in the mine as mushroom-growers, were killed.

One person died when she was projected against a pillar wall by the resulting air blast. On the short term (weeks, months), such collapses are preceded by a striking acceleration of pillar- and roof fracturing and spalling, by cracking sounds and by rock dust falling from the roof. Unfortunately such signs were often ignored.

Extensive field studies showed that two types of largescale pillar collapse exist (Fig. 1).

In most cases type A applies, which is characterised by downward movement of the rock overburden along joints or collapse-induced faults. These faults dip towards the area still standing and intersect the whole rock overburden. The over- lying soil flows into the rock depression, and a subsidence trough is formed, bounded by sinkholes and normal faults with vertical offsets of up to more than one meter. The other type B occurs by mere deflection of the rock overburden, without disruption over its full height at the margins. This type was observed at two collapses of mined areas of a relatively wide span of more than $150 \mathrm{~m}$. The surface subsidence is more or less the same as for the first type.

\subsection{Assessment of the large-scale pillar collapse potential}

The assessment of the large-scale pillar collapse potential has been explained in previous publications (Bekendam, 1998, 2000, 2004). For the understanding of this paper only some basic concepts are dealt with. The stability of an individual pillar can be determined by using a safety factor SF, which is the ratio of the pillar strength $S_{\mathrm{p}}$ and the mean vertical pillar stress $S$. The latter is calculated by the well-known tributary area method (Goodman et al., 1980) The following formula, a modified version of that of Goodman et al. (1980), applies well to the strength of the limestone pillars in Limburg:

$S_{\mathrm{p}}=\mathrm{UCS} \times(0.875+A / C H)$,

where $A$ and $C$ denote the area and circumference of the basal plane of the pillar, $H$ is the pillar width and UCS the unconfined compressive strength of the limestone. Additionally, the large-scale pillar stability must be taken into account, which is defined by Bekendam (1998) as a safety factor, to be achieved by dividing the total load carrying capacity of all pillars together by the total overburden load:

$\mathrm{SF}_{\text {tot }, 0}=\frac{\Sigma\left(S_{\mathrm{p}} \times A_{\mathrm{p}}\right)}{\Sigma\left(S_{\mathrm{ov}} \times A_{\mathrm{t}}\right)}$

To describe the amount of pillar damage more or less quantitatively by visual inspection and to validate calculated safety factors, the pillar classification system of 1998 was refined and extended in (Bekendam, 2000). In this system pillars of class 0 are not affected at all by fracturing, and class 1 pillars do not show fractures of more than $1 \mathrm{~mm}$ width and more than a few decimetre length. In a stability analysis these pillars are considered as (more or less) intact. The amount of fractures and their width and length increases from class 2 to 6 . From class 4 onwards major (more than $1 \mathrm{dm}$ deep) spalling has arisen. Class 6 pillars are affected by spalling at all sides. Class 2 to 6 pillars are considered as failed and just have some residual strength. Later class 7 was added for fundamentally destroyed pillars in collapse areas, where shortening has increased to several decimetres or even more than one metre, contrary to class $0-6$ pillars where shortening is limited to a few centimetres. Validation of safety factors has been carried out often by statistical analyses of mines that all consist of pillars of the same shape and size (e.g. van der Merwe and Mathey, 2012). In such an analysis 


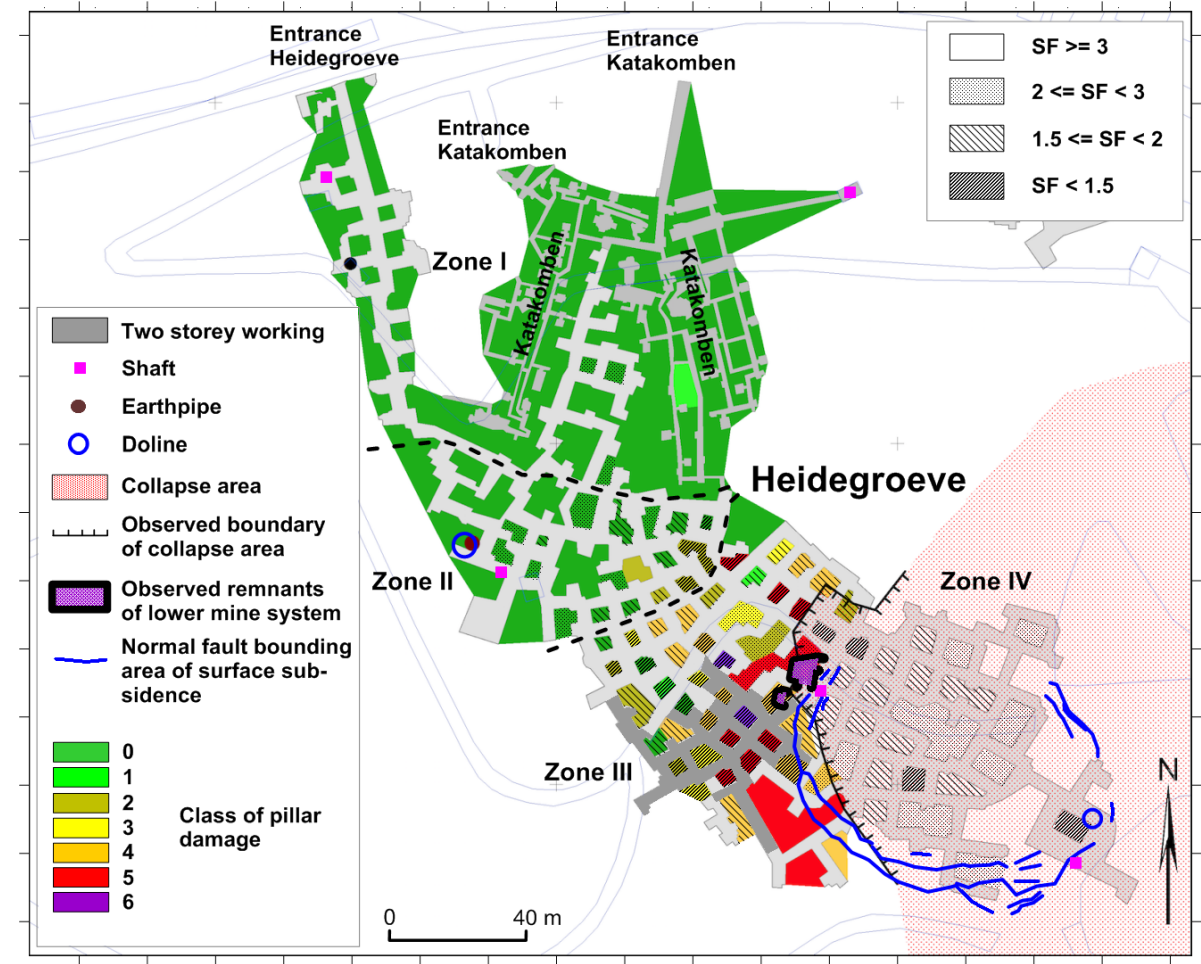

Figure 2. Map of the Heidegroeve.

each mine represents one case. Such a study is impossible for the limestone mines of Limburg where pillars are generally irregular and vary in shape and size throughout one mine. Experience with several tens of mined areas (e.g. Bekendam, 2000) shows that a total safety factor of two or more ensures sufficient large-scale pillar stability. A value of less than 1.5 proved to be insufficient, and a value between 1.5 and 2 is dubious. Generally class $0-1$ pillars have individual safety factors exceeding 1.5 , while the safety factors for class $2-3$ pillars are less than 2 and those for class $4-6$ pillars are less than 1.5 .

\section{The collapse of the Heidegroeve}

\subsection{Geometry, geology and history of the mine}

The Heidegroeve is excavated in the lower level of the Limestone of Meerssen (Felder, 1979), which forms part of the Formation of Maastricht. It is situated on the southwestern side of the town of Valkenburg below the wooded area of the Polferbos. The mine extends about $300 \mathrm{~m}$ to the southeast of the entrance under a rising topography, where its depth reaches a maximum value of almost $50 \mathrm{~m}$. Apart from the area in the direct vicinity of the entrance, the overburden consists of 17 to $24 \mathrm{~m}$ of limestone, covered by mainly clayey sands and some metres of gravel and loess.
Most pillars are more or less rectangular with horizontal dimensions of 4 to $12 \mathrm{~m}$. Their height is about $2 \mathrm{~m}$ in the major part of the mine, but in the central part an additional $2.6 \mathrm{~m}$ of the overlying strata was extracted (Fig. 2). The galleries are usually 3.5 to $4 \mathrm{~m}$ wide. Joints rarely occur.

The excavation of the mine started in the beginning of the nineteenth century from the entrance galleries of the present "Katakomben", mainly to create a depot for gunpowder fabricated in the factory nearby (Habets, 1988). After the closure of the gunpowder factory mining continued, now mainly for the purpose of extracting building stone. In 1909 a part of the mine was separated to create an imitation of the Roman catacombs (Katakomben), which still serve as a tourist attraction. A new entrance was made to the west of the existing one for further exploitation of the Heidegroeve. In the 1920's the overburden stress in the southern part of the mine proved to be so high that the rock closed on the steel cutting saws. The quality of the stone was moderate and in the 1930's the limestone exploitation came to an end.

In 1944 the Germans converted the mine into a bombproof factory for the production of electronic components for aeroplanes (Silvertant, 2004). They made a new mine plan with an accuracy of $\pm 10 \mathrm{~cm}$. When comparing this plan with the previous ones it becomes evident that they excavated some additional galleries, reducing pillar size. Many pillar corners were rounded off and reinforced with brickwork. In Septem- 


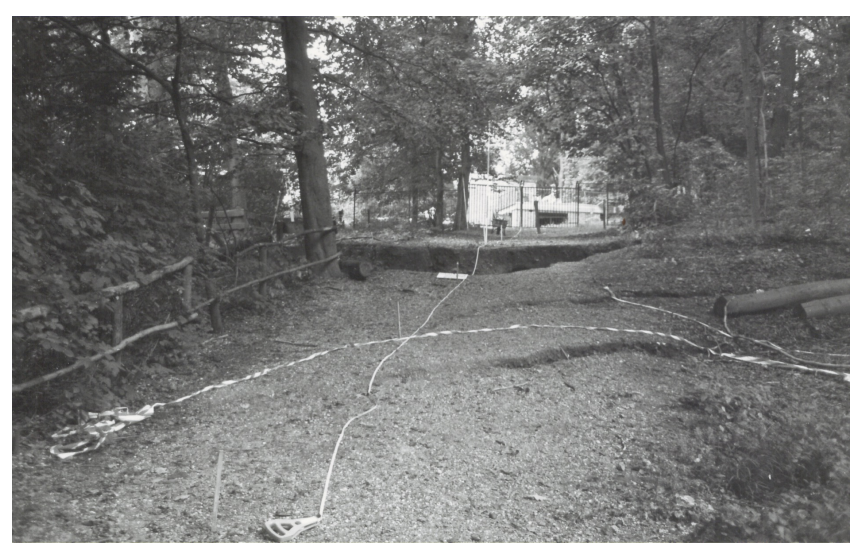

Figure 3. Normal faults on the footpath just north of the restaurant in the background (Courtesy of David George Price).

ber 1944 the town of Valkenburg was liberated when the factory was just operating.

After the war the mine was used for mushroom growing and an attempt was made to breed worms for fishing bait. At least up to the 1970's the mine appeared to be stable. It is not known when exactly the deterioration of the mine set in, but in the summer of 1987 significant pillar cracking and spalling, especially in and near the future collapse area, was reported by the State Inspectorate of Mines, and the mine had to be abandoned.

\subsection{Surface subsidence}

In the evening of June 1988 walkers in the Polferbos observed cracks in the footpaths and raised the alarm (Fig. 3). An examination of the mine showed that 0.4 ha in the southeastern part of the mine had collapsed. The collapse was recorded by seismographs in the region. The shock lasted less than $45 \mathrm{~s}$ with about $10 \mathrm{~s}$ of strong motion. The subsidence at the surface and the pillar damage underground are described by Price (1989).

At the surface an elliptical subsidence area of about $100 \mathrm{~m}$ by $70 \mathrm{~m}$, bounded by normal faults, had developed (Fig. 2). A restaurant, just $30 \mathrm{~m}$ to the south of the subsidence area, was fortunately undamaged. The outer normal faults showed apertures of up to $40 \mathrm{~cm}$ and downward displacements of up to $80 \mathrm{~cm}$ towards the subsidence area. These faults were often accompanied by more or less parallel antithetic faults with less apertures and downward displacements, resulting in a graben-like structure. A fence, situated inside the collapse area, was damaged and underwent horizontal shortening of about $10 \mathrm{~cm}$. Close to the easternmost shaft a doline of about $1.5 \mathrm{~m}$ depth had developed.

\subsection{Survey of the collapse geometry}

In 1992 a more detailed survey of the pillar damage was carried out and also the boundary of the collapse was investi-

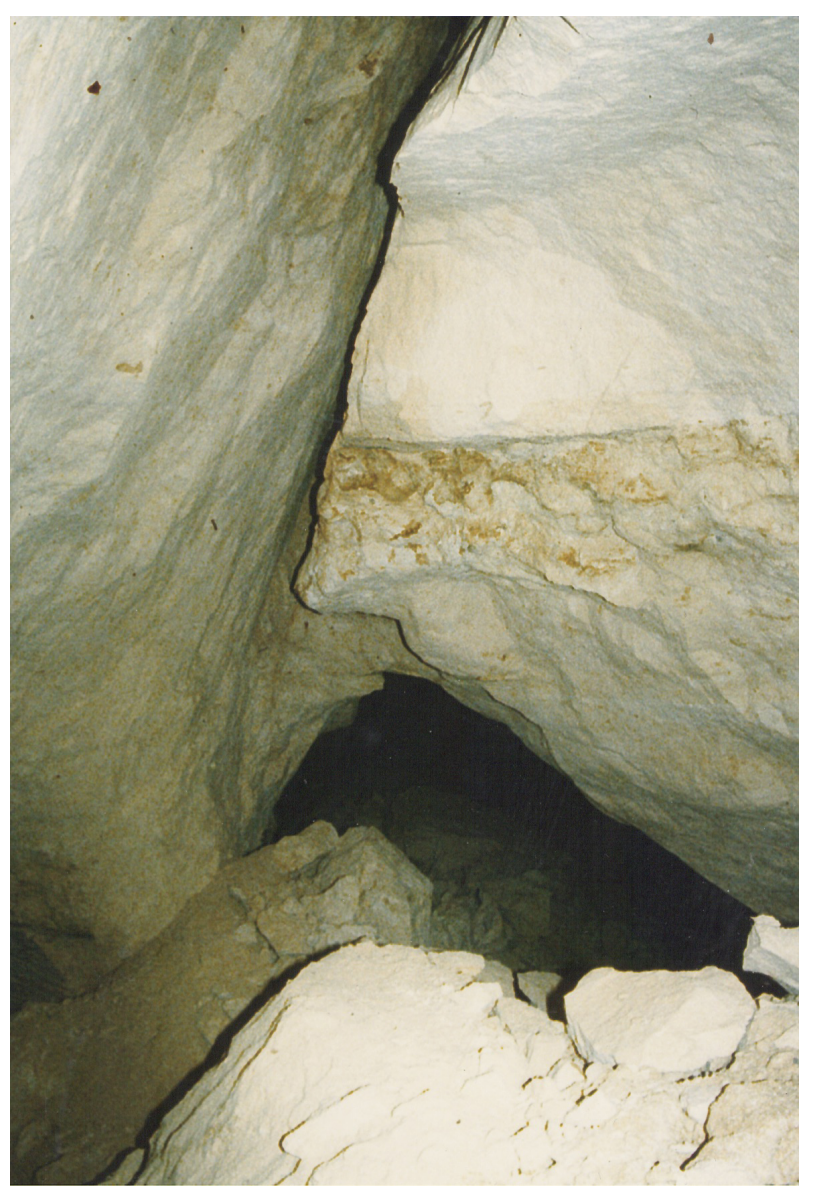

Figure 4. Collapse-induced fault in the rock overburden of the Heidegroeve.

gated (Bekendam, 1998). The limestone overburden proved to be subsided along faults dipping at an angle of 65 to $80^{\circ}$ towards the not-collapsed part of the mine (Fig. 4). Thus, the collapse is obviously of Type A. At the basis of the faults often roof falls had occurred resulting in arches up to $8 \mathrm{~m}$ above the original mine roof. Below the arches debris piles reached levels mostly exceeding that of the original mine roof. From the top of the debris piles the faults could be observed up to more than $10 \mathrm{~m}$ above the original roof, and the fault orientation seemed to be unchanged as far as could be seen. There is no infill of soil, probably to the considerable thickness of the rock overburden. The fault showed an opening of several decimetres, which is a logical consequence of the collapse geometry. A remarkable feature is that an open fault proved to be present in the mine floor, near the bunker shaft at the boundary of the collapse.

\subsection{Evidence of a lower mine system}

In the analysis of 1998 three important findings emerged:

1. The safety factors of the pillars inside the collapse area are such that this part of the mine should have been sta- 


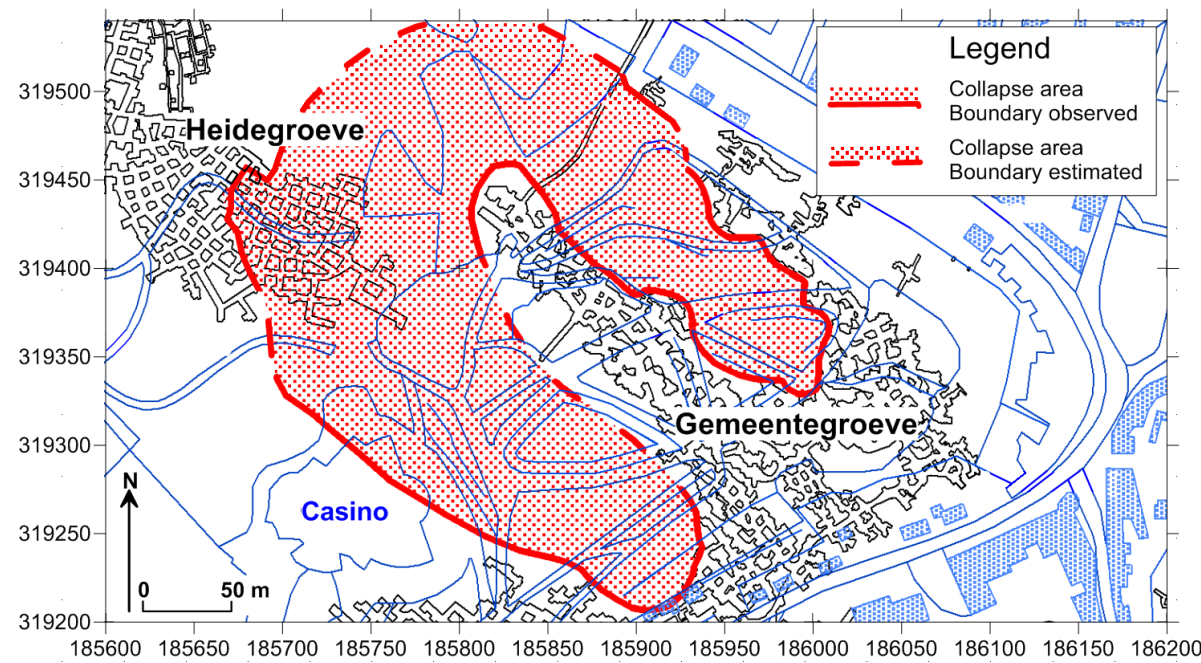

Figure 5. The collapse area between the Heidegroeve and the Gemeentegroeve.

ble. Moreover, the pillars outside the collapse area show generally much lower safety factors.

2. Between the Heidegroeve and the northwestern part of the nearby Gemeentegrot an extensive collapse area exists, comprising unmapped and inaccessible, more or less intact workings (Fig. 5). More than 200 borings for a site investigation for the erection of a new casino showed both collapsed- and not-collapsed (but possibly damaged) mine workings in this area. The Gemeentegrot and the mine workings at its perimeter were excavated in the Limestone of Nekum, which is about $5 \mathrm{~m}$ below the Limestone of Meerssen of the Heidegroeve (Felder, 1979).

3. The observed open fault in the mine floor could only have developed if open space was present at a lower level.

These facts are strong indications that the collapse of the Heidegroeve was related to an instable mine working underneath. However, a final proof was not yet delivered.

\subsection{Reanalysis of the pillar stability}

In 2010 and 2012 new surveys of the Heidegroeve were carried out (Bekendam, 2012) concerning the safety of tourists in the Katakomben and bat researchers in the Heidegroeve. All pillars were classified again, but now in more detail according to the system of 7 classes (Fig. 2). In the northwestern part (zones I and II) hardly any pillar damage has developed, but in zone III, adjacent to the collapse area, the majority of pillars are affected by serious cracking and spalling (class 4-6). Often the brick cladding had parted from the pillar walls and fallen on the floor. The pillars in the collapse area are to be characterized as class 7 by definition, but this is not indicated in Fig. 2 to keep the map organized.
Also the pillar safety factors were recalculated using Eq. (1), with a UCS of $2.0 \mathrm{MPa}$ and densities of the limestone and the overlying soil of $1.6 \times 10^{3}$ and $2.0 \times 10^{3} \mathrm{~kg} \mathrm{~m}^{-3}$ respectively. In Fig. 6 pillar stress and pillar strength are depicted for zones II-III and zone IV separately. For zones II and III all more or less intact pillars (class 0 and 1) except four have safety factors exceeding 1.5 . Most pillars with moderate damage (class 2 and 3) have safety factors of less than 2 except two cases, and the majority of seriously damaged pillars (class 4-6) have safety factors of less than 1.5, except for nine cases. So far the relationship between pillar class and safety factor is as to be expected. However, nearly all class 7 pillars of the collapse area (zone IV), 26 of the total 30 pillars in the area, have safety factors of more than 1.5. Just 4 pillars show a safety factor of less than 1.5 . These safety factors are abnormally high for a collapsed area. The safety factors are indicated in Fig. 2 as well.

Moreover, the total safety factor of the pillars inside the collapsed area of zone IV proved to be 2.52 . A collapse of an area with such a high safety factor is normally impossible. The still standing zone III shows a much lower total safety factor of just 1.76. This value represents dubious large-scale pillar stability. The total safety factor of the more or less undamaged zone II is 2.92 .

\subsection{Discovery of open galleries of a lower mine system}

In 2012 a descent was ventured into the above-mentioned fault in the mine floor, near the bunker shaft at the boundary of the collapse. The fault proved to be about one meter wide and dips at an angle of about $70^{\circ}$ in the direction of the not-collapsed part of the mine, more or less in the extension of the fault in the roof of the Heidegroeve. Due to fallen rock debris the slope was reduced to about $45^{\circ}$. Great care was taken not to dislodge blocks from the hanging- and foot- 


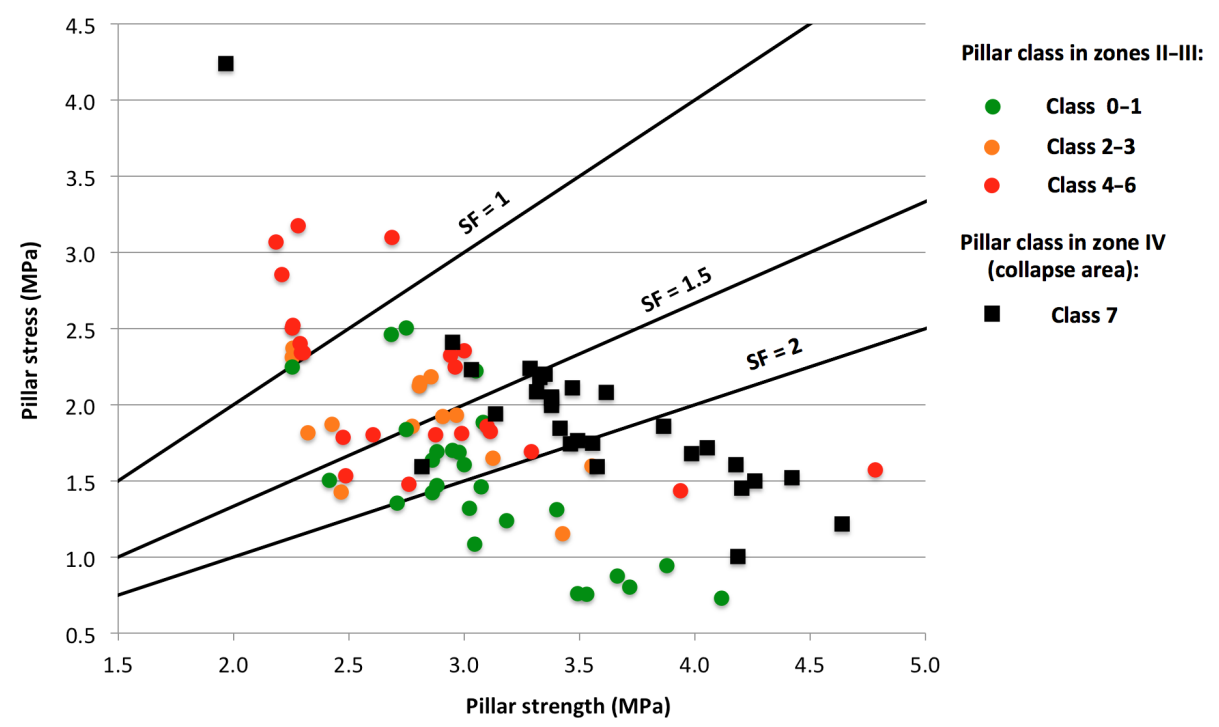

Figure 6. Pillar stress and pillar strength for pillars of different pillar classes in zones II-III and zone IV.

wall of the fault. At about $3.5 \mathrm{~m}$ below the floor of the Heidegroeve two small chambers were discovered (Fig. 7). Indeed, the presence of a lower mine system was now proven! The southwestern chamber is just 2 by $4 \mathrm{~m}$, and is bounded in the east by the debris-covered fault and at the other three sides by more or less intact walls. The larger northeastern one measures about $12 \mathrm{~m}^{2}$. The walls of this chamber are largely fractured and spalled (class 5-7). The northeastern chamber is not only limited by debris in the south, near the fault, but also at it northeastern side. Both chambers are about $2 \mathrm{~m}$ high and contain saw- and chisel marks from exploitation, which dates from the 17th or 18th century (Wiel Felder, personal communication, 2012). The debris blocks off any passage to possible openings further inside the collapse area at the lower mine level.

\subsection{Exploration of the collapse area of the Heidegroeve}

In 2018 the collapse area at the level of the Heidegroeve was explored twice. The only access into the collapse was near the bunker shaft. The remainder of the collapse boundary was blocked off by roof debris. As in several other collapse areas, openings existed between the debris fragments. However, due to roof collapses up to more than $8 \mathrm{~m}$ above the original roof level and the bulking effect of the resulting debris, sometimes just a few decimetres remained for passage. Apart from the local roof collapses above galleries, the rock overburden has collapsed as one rock mass, albeit intersected by faults locally. Therefore over several galleries the roof was observed to be more or less intact. The pillars of originally $2 \mathrm{~m}$ height were mostly strongly fractured and spalled (class 6-7) but not shortened more than a few decimetres. Locally the concrete mine floor, made by the Germans, was tilted at an angle of up to $45^{\circ}$ resulting in height dif-

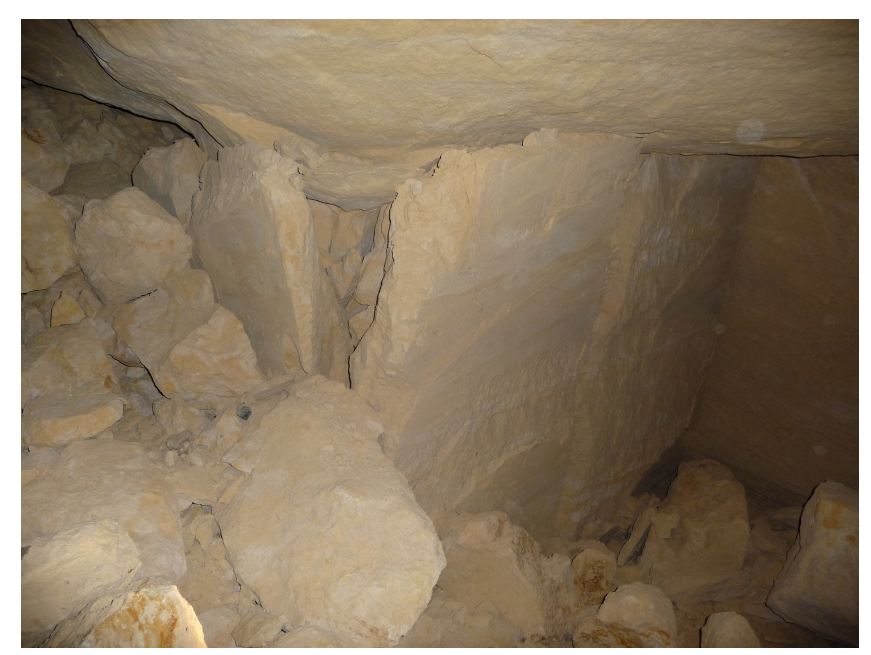

Figure 7. Collapsed pillar in the northeastern chamber of the lower mine system. The debris slope to the left gives access to this mine level.

ferences of about one metre (Fig. 8). This interesting phenomenon was most probably brought about by punching of pillars of the lower mine.

\section{Conclusions}

Near the boundary of the collapse area of the Heidegroeve, chambers were discovered at the lower mining level of the nearby Gemeentegroeve. The significant shortening of the pillars (mainly class 7) and the debris piles blocking off the chambers show that the lower mine has collapsed as well. This is also confirmed by the collapse-induced fault from the Heidegroeve down to the remnants of the lower mine work- 


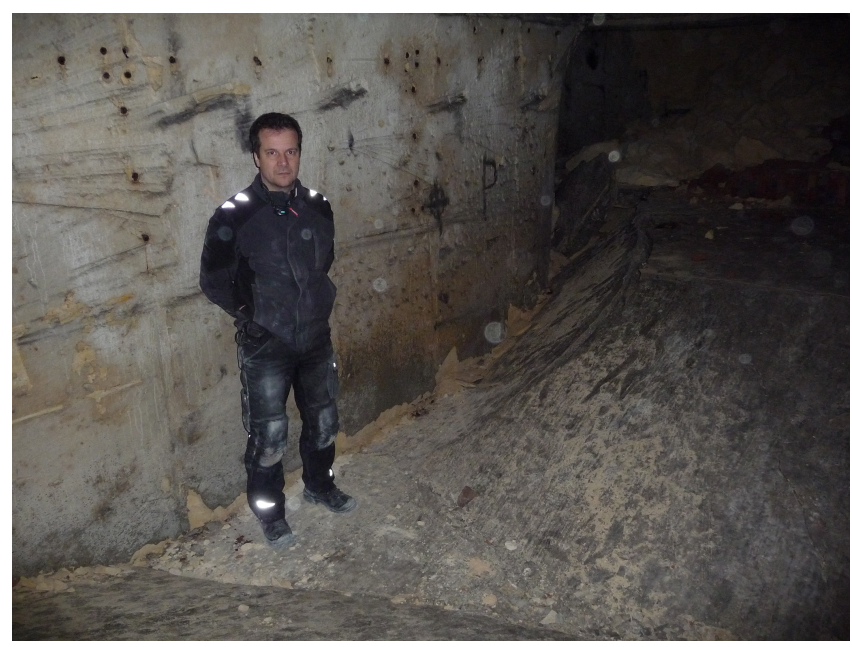

Figure 8. The strongly tilted mine floor in the collapse area of the Heidegroeve.

ing. This fault was not present in the mine floor of the Heidegroeve before the collapse of 1988 . This means that the lower mine working collapsed together with the Heidegroeve. The strongly tilted parts of the mine floor inside the collapse area of the Heidegroeve show that pillars of the lower mine system had punched through the about $3.5 \mathrm{~m}$ thick interlayers. On the other hand, pillars of the Heidegroeve have probably punched through the interlayers inside galleries below. It is unavoidable that pillars of the Heidegroeve have been created above galleries of the lower mine and vice versa. The pillar deterioration in zone III preceding the collapse is probably due to an increase in pressure due to the abutment pressure of the lower working (Bekendam, 1998). Such a feature was also described by Kratsch (1997). About 50 years elapsed since the end of the exploitation of the Heidegroeve until creep deformation reached an accelerating stage giving rise to the collapse.

Data availability. The data can be assessed by contacting the author.

Competing interests. The author declares that there is no conflict of interest.

Special issue statement. This article is part of the special issue "TISOLS: the Tenth International Symposium On Land Subsidence - living with subsidence". It is a result of the Tenth International Symposium on Land Subsidence, Delft, the Netherlands, 17-21 May 2021.
Acknowledgements. Arnout Sluijsmans of Mergelbouwsteen Kleijnen, Rob Swaans of the Jezuietenberg Foundation and Wiel Felder of the Municipality of Valkenburg are gratefully acknowledged for their assistance during the underground surveys.

\section{References}

Bekendam, R. F.: Pillar stability and large-scale collapse of abandoned limestone room and pillar mines in South-Limburg, the Netherlands, PhD thesis, TU Delft, Delft, the Netherlands, 361 pp., 1998.

Bekendam, R. F.: Stability assessment of underground limestone quarries, GeoControl rapport M00011, by order of: State Inspectorate of Mines, GeoControl, Maastricht, the Netherlands, 76 pp., 2000 (in Dutch).

Bekendam, R. F.: Stability and subsidence assessment over abandoned limestone room and pillar mines, in: Engineering geology for infrastructure planning in Europe, 2004 IAEG Conference, 3-7 May 2004, Liege, Belgium, 657-670, 2004.

Bekendam, R. F.: Inventory of the pillar stability of the Wijngaardsberggroeve, Kleinberggroeve Noortd en Zuid, Groeve aan de Heide, Vogelbosgroeve en Heidegroeve, by order of: VZZ, GeoControl, Maastricht, the Netherlands, 33 pp., 2012 (in Dutch).

Felder, W. M.: The stratigraphical position of the calcarenite mines in the Upper Cretaceous of South-Limburg, part1: the mines near Valkenburg and Sibbe, Natuurhistorisch Maandblad, 68, 21-25, 1979 (in Dutch).

Goodman, R., Korbay, S., and Buchignani, A.: Evaluation of collapse potential over abandoned room and pillar mines, Bull. Ass. Engng. Geol., 17, 27-37, 1980.

Habets, J.: The Heidegroeve served various purposes, Geulrand, Valkdruk, Valkenburg, the Netherlands, 24, 1988 (in Dutch).

Hustrulid, W. A.: A review of coal pillar strength formulas, Rock Mech., 8, 115-145, 1976.

Kratszch, H.: Mining subsidence engineering, 3rd edn., Deutscher Markscheider-Verein, Bochum, Germany, 844 pp., 1997 (in German).

Price, D. G.: The collapse of the Heidegroeve: a case history of subsidence over abandoned mine workings in Cretaceous calcarenites, in: Proceedings International Chalk Symposium, 47 September 1989, Brighton, UK, 503-510, 1989.

Silvertant, J.: The limestone mines of South-Limburg in the German war plans 1943-1944, 1st edn., Silvertant, Maastricht, the Netherlands, 56 pp., 2004.

van der Merwe, J. N. and Mathey, M.: Update of coal pillar data base, Strength formulae and probability of failure for South African coal mining, Coaltech Research Association, Johannesburg, South Africa, 77 pp., 2012. 